\title{
Working in lockdown: the relationship between COVID-19 induced work stressors, job performance, distress, and life satisfaction
}

\author{
Parul Kumar $^{1} \cdot$ Neha Kumar $^{2} \cdot$ Priti Aggarwal $^{3}$ (D) Jasmine A.L. Yeap ${ }^{4}$ \\ Accepted: 2 March 2021 / Published online: 14 March 2021 \\ (C) The Author(s), under exclusive licence to Springer Science+Business Media, LLC, part of Springer Nature 2021
}

\begin{abstract}
Background \& aim In the wake of COVID-19, organizations all over India have closed their premises and shifted to work from home policy to curb the further spread of the virus. This has led to increased stress and anxiety among employees, which explicably affects their satisfaction with life. Thus, the present study analyses the effect of COVID-19 induced stressors (role overload, lifestyle choices, family distraction, and occupational discomfort) on employees' distress levels and job performance. Subsequently, the impact of such distress and job performance on the employees' life satisfaction is analyzed during the lockdown period.

Methodology Data was collected from 433 working professionals of private and public organizations in the Delhi and NCR region of India during India's third and fourth phase of lockdown via a survey, which was distributed online. Partial least squares structural equation modelling was applied first to establish the validity of this study's model (measurement model validity) and subsequently test the hypothesized relationships in the model (structural model).

Results The COVID-19 induced stressors, i.e., role overload, lifestyle choices, and occupational discomfort, were significant predictors of distress during the lockdown. It has been found that role overload and change in lifestyle choice did not significantly affect job performance. Family distraction, occupational discomfort, and distress were significant in impacting job performance, with distress being the most significant one. During the COVID-19 pandemic, life satisfaction has reduced due to a significant increase in distress levels and lowered job performances.
\end{abstract}

Keywords COVID-19 - SARS coronavirus · Job performance $\cdot$ Life satisfaction · Family distraction · Role overload . Occupational discomfort

Priti Aggarwal

Priti3789@gmail.com

Parul Kumar

dr.parulk1808@gmail.com

Neha Kumar

kumarneha89@gmail.com

Jasmine A.L. Yeap

jasmine@usm.my

1 Department of Business Administration, Maharaja Agrasen Institute of Management Studies, Delhi, India

2 The NorthCap University, Gurugram, India

3 Delhi School of Business, Vivekananda Institute of Professional Studies - Technical Campus, Delhi, India

4 School of Management, Universiti Sains Malaysia, Penang, Malaysia

\section{Introduction}

Globalization and technological advancements have contributed to economic growth, enhanced our standard of living, and provided innumerable means of comfort (Abdel-Hadi 2012). However, the other by-products like cut-throat competition, enhanced workload, extreme working conditions, and increasing job demands cannot be ignored, which are significantly contributing to occupational stress (Prasad and Vaidya 2020). Occupational stress or job stress is the pressure that an employee feels due to employment-related factors. When the expectations/demands put on an employee do not match with the available resources, i.e., knowledge, skill, or abilities, they tend to experience stress (Colligan and Higgins 2006). Further, the changing society, cultural environment, and lifestyle affect employee performance and disturb the work-life balance. The past studies have reported several ill-effects of work-related stress, namely hypertension, diabetes, insomnia, asthma, musculoskeletal disorders, and others (Padma et al. 2015). This impact of occupational stress could be seen across 
all the countries, professions, on all categories of employees, families, and society in general.

The novel coronavirus has further aggravated these ill effects. The majority of the organizations, be it educational institutions, schools, corporate houses, some businesses, and government offices, overnight adopted the work from home (WFH) concept (Shareena and Shahid 2020). The novel coronavirus, which initially originated from Wuhan, China, in December 2019, has, to date, spread across all the countries in the world. The World Health Organization (WHO) declared the coronavirus epidemic a 'pandemic'(World Health Organisation (WHO) 2020). Thus, in an unparalleled attempt to control the spread of the COVID-19 outbreak, the Government of India enforced lockdown in the entire nation on March 25th, 2020. It resulted in the suspension of all economic activities apart from the supply of essential goods. The people engaged in the field of medicine, journalism and essential commodities were exempted from the lockdown and rest of the working class has been directed to shift to remote working. Before the pandemic, WFH was a matter of privilege offered by the corporates and big business houses, as it provides flexibility and discretion; however, it has now become the new normal. This overnight shift to WFH has been new to most of the professionals. Thus, a lot of stressors have come into existence, possibly affecting their job performance, causing distress, and diminishing life satisfaction. The COVID-19 has tumbled up everyone's daily routine and everything; business, schools, and the economy (Gautam and Sharma 2020).

Maintaining a boundary between work and non-work has become challenging (Ramarajan and Reid 2013). This discomfort has been demotivating people and often leading to missing the deadlines, thus further causing distress and/or anxiety. In line with the results of the previous epidemic (SARS, equine influenza, Ebola and others (Hawryluck et al. 2004; Taylor et al. 2008) studies, the present studies, performed in China and Italy, have also reported that people have been suffering from serious mental health issues due to Covid-19 epidemic (Mazza et al. 2020; Wang et al. 2020a). In the Indian context, to date, a limited number of research studies have been carried out on the psychological impact of both COVID-19 and lockdown. These studies have either been concentrating on perceived mental health care need (Roy et al. 2020) or the impact of the epidemic on the specific caregivers, namely, healthcare workers (Chew et al. 2020) and/or pharmacy students (Suryadevara et al. 2020). However, there has been only a handful of research studies that have attempted to gauge the impact of COVID-19 and lockdown on the working professionals, i.e., how they have been managing WFH with limited resources, along with their household responsibilities, child care, elderly care, and the work pressure to retain the job. Professionals have been struggling very hard to manage both the work and home roles with the challenge of resource constraints as well. This is likely to influence their personal and professional lives, which might lead to discomfort and distress.

Thus, the present study analyses the effect of COVID-19 induced stressors (role overload, lifestyle choices, family distraction, and occupational discomfort) on employees' distress levels and job performance. Subsequently, the impact of such distress and job performance on the employees' life satisfaction is analyzed during the lockdown period.

\section{Theoretical Underpinnings}

The majority of the workforce today has been combining work and family responsibilities. Work and family issues have an impact on employees, families, and organizations. The work-family literature often states that work and family roles are often problematic and lead to conflicts (Greenhaus and Beutell 1985). In contrast, some researchers contradict that work and family roles are mutually enriching (Greenhaus and Powell 2006). Various researchers have conducted studies based on the role theory (Levinson et al. 1965) to analyze work and family conflict. The theory states that people find it difficult to maintain multiple roles and cannot perform each role successfully, leading to a conflict (Greenhaus and Beutell 1985; Levinson et al. 1965). However, the work-family perspectives should be taken into consideration with the workhome resources. The conservation of resource (COR) (Hobfoll 1989, 2002) theory builds the theoretical model for work-home resources. The COR model comprehends several stress theories and is one of the most influential stress theories amongst all (Hobfoll 1989). The model recommends that an individual acquires and maintains resources. Stress is a reaction to an environment wherein a person experiences a threat or an actual loss of resources. These resources might be conditions, objects, personal characteristics, and emotional and physical energy. Hence, loss of or threat to lose these resources may lead to stress among the people. An additional insight covered by the COR model is the prominence of threatened resources, which states that critical events are also a cause of stress.

Based on this theoretical perspective, the present research conceptualizes COVID-19 mandatory WFH induced stress factors. A working professional finds it difficult to manage work and home responsibilities in the WFH scenario. The struggle between work and home domains is because of his inability to manage the resources (ten Brummelhuis and Bakker 2012) as the resources are finite (Becker 1965; Goode 1960), and it becomes difficult to manage and fulfill the obligations effectively at both work and home with limited resources (Greenhaus and Beutell 1985; Halbesleben et al. 
2009). Based upon COR theory, this reduction in employees' resources, both in terms of physical and emotional, has an impact on the performance of the employees (Xia et al. 2019). Thus, a professional has been unable to manage both the work and home roles simultaneously. This might be leading to an increasing level of anxiety and job dissatisfaction (Hobfoll 2002). Applying the COR theory \& role theory in the WFH scenario, the authors attempt to understand how an employee has been managing and performing the responsibilities of work and home with the limited resources. Based on this, the study shall further assess how this possible conflict (in managing the roles properly) influences the performance on the job, which has been leading to the distress level.

\section{Research Model and Hypothesis Development}

The WFH as a phenomenon was a matter of research since the last decade; however, it has now become an alternative strategy for most organizations due to the current pandemic. COVID-19, apart from impacting one's health, has also affected the social and economic lives of the people. The technological developments as we know not only impact the organizations but also influence the people's lifestyle and social lives. Everything has two sides, or we can say two opinions; the same is with the WFH perspective. One side of opinion is that it helps keep a work-life balance between one's work and social life. On the same lines, others believe that they can spend more time with their families as work from home offers them a lot of flexibility, and traveling time is also saved (Daniels 2000). While another side of opinion is that employee productivity reduces, working hours extend, becomes challenging to manage time between work and family and in some cases decline in job performance. Hence, there has been a flip side as well as a bright side to WFH.

However, for a few of the working professionals, especially females, it becomes a difficult task to manage the WFH owing to domestic responsibilities in addition to official work (Crosbie and Moore 2004). In the present scenario, this family work conflict has widened more with the fact that both the parents have been working from home and the child is also at home. Hence, this has created lots of difficulties in managing the work and the family together during this time. Work is affecting family, and family is affecting work (Frone et al. 1992; Gutek et al. 1991). Due to distractions and insufficient time to perform the work and family roles, the key mental health issues have been cropping up, i.e., dissatisfaction, work tensions, depression, stress, and others (Frone et al. 1991; Greenhaus et al. 1997).

Life satisfaction refers to the feeling of well-being with oneself in one's surroundings (Cobos-Sanchiz et al. 2020). In their study among 509 men and 396 women of Spain, they found that men experience higher psychological distress and reduced life satisfaction with a larger number of work-related events and changes as compared to the women. They used the Satisfaction with Life Scale (Diener et al. 1985) to measure life satisfaction. Distress has been considered as a predictive factor for life satisfaction (Fang et al. 2019). Previous research documents state that high perceived stress predicts low satisfaction (Extremera et al. 2009; Hamarat et al. 2001; F. Wang and Boros 2019). The levels of life satisfaction also get influenced with particular life domains (Stubbe et al. 2005). The domain satisfaction reflects a perception of a particular aspect of one's life like satisfaction with one's job, marriage, house, and others.

Further, it has been recognized that domain satisfaction and life satisfaction are substantially correlated (Pavot and Diener 2008). In the important life domains like the quality of social and marital relationships, success at the workplace, physical and mental health, empirical research shows that life satisfaction can be beneficial. Individuals reporting high life satisfaction have stronger social relationships (Diener and Seligman 2002) and marital satisfaction (Glenn and Weaver 1981). Moreover, it has been found that open acknowledgment instead of denial of emotions under stressful conditions result in better life satisfaction (Extremera et al. 2009). In a longitudinal study carried out in 1972-73 among U.S. workers, the authors found that job satisfaction and life satisfaction are positively related; however, the effect of life satisfaction on job satisfaction was significantly stronger than the effect of job satisfaction on life satisfaction (Judge and Watanabe 1993).

People are more likely to experience distress due to stressful life events, particularly women, which lead to work disruptions (R. C. Kessler and McLeod 1984) and, as a result, impacts their work performance (Bhagat 1983). Thus, employees' workrelated factors (Bacharach et al. 1990), personal factors (Adams et al. 1996), situational and environmental factors (Wang et al. 2020b) lead to different forms of psychological distress (Enshassi et al. 2016; Johari and Omar 2019). This outbreak of the pandemic has not only been affecting people physically (illness, hospitalization) but also financially (redundancy, financial insecurity (McKibbin and Fernando 2020) and psychologically (fear, loneliness). The present study takes into consideration four independent variables - two in the form of personal stressors and the other two in the form of work stressors. The lifestyle choices and family distractions represent the personal stressors, whereas role overload and operational discomfort represent work stressors. These stressors have been regressed on distress and job performance to analyze the overall impact on life satisfaction during the COVID-19 pandemic.

\section{Lifestyle Choices}

Lifestyle choices such as eating habits, alcoholism, sleeping pattern, health orientation, and others differ from individual to 
individual. However, these personal lifestyle choices can be directly linked with psychological health conditions such as anxiety, depression, and distress (Fried 2017; Gariepy et al. 2010). Consistent evidence provides that a high degree of correlation exists between increased stress and increased sedentary screen time (Biddle and Asare 2011). It has also been established that the poor lifestyle choices have a severe impact on the employee's job performance, resulting in increased costs to the organizations, in the form of sick leave and poor employee morale (Hassard et al. 2018). Healthy lifestyle choices like a healthy diet, avoiding alcohol, proper sleep, and others have proven to increase an individual's resistance to stress (Prasad et al. 2016). Psychological stress and physical activity have been believed to be reciprocally related and often leads to physical inactivity (Stults-Kolehmainen and Sinha 2014). In the Scottish Health Survey, it has been found that daily physical activities lead to a lower risk of psychological distress (Hamer et al. 2009). Therefore, an individual's lifestyle choices have been taken as a potential predictor of distress. In this paper, the construct of lifestyle choices has been based on items, namely, exercise, sleep pattern, eating habits, and weight management.

H1. Positive lifestyle choices reduce distress.

H2. Positive lifestyle choices enhance job performance.

\section{Family Distractions}

Employees working from home face challenges in the form of family distractions. During this ongoing COVID-19 pandemic, the help and support system in the form of day-care facilities, schools, colleges, domestic servants, and others are no longer available to the majority of the households. Thus, almost everyone has been sharing the household responsibilities, family obligations, along with work commitments. Hence, it is quite a possibility that many times work suffers and a few of the times family suffers. In the work-life literature, it has been recognized that individuals may be actively participating in one role while at the same time being distracted by thoughts, emotions, or demands associated with another role (Ashforth et al. 2000; Frone et al. 1992). The prior researchers have also explored the individual's psychological participation in a specific role (Adams et al. 1996; Fox and Dwyer 1999). From this viewpoint, high levels of psychological participation in a particular role (family) can cause a person to be mentally distracted while physically attending his/her other role (work). According to Spillover theory, moods, emotions, stress, and thoughts created in a role domain often flow to other domains (Williams and Alliger 1994). This ultimately affects the person's mental health in terms of increased stress and depression levels or maybe more distress (Prasad and Vaidya 2020).
H3. Family distractions increase distress.

H4. Family distractions negatively affects job performance.

\section{Role Overload}

The flexibility of WFH generally gives an impression that employee has saved upon the time of commutation, therefore, can devote the saved time to working more. Even it is also of the view that, as the employee is at home, then work hours can extend easily. Hence, leading to an increase in daily working hours (McKeever 2020). These aspects have been combined to form another COVID-19 work stressor, i.e., role overload. Thus, it is defined as the perception of having too many workrole tasks and not having enough time to do them (Bacharach et al. 1990; Katz and Kahn 1978). It estimates the degree to which the job requisites exceed the personnel and workplace resources (Caplan et al. 1975). This has also been recognized as one of the three elements of work stress (Kahn 1980), and any employee can feel stress, anger, and frustration (Marini et al. 1995) due to role overload.

H5. Role overload increases distress.

H6. Role overload negatively affects job performance.

\section{Operational Discomfort}

The pandemic has forced most employers to implement WFH policy for their employees, practice social distancing, and limit the spread of the virus. WFH in pandemic times has also resulted in cross-role disturbances and regular commotions, thereby escalating difficulties of meeting work and family requirements (Chen et al. 2009). However, amid the COVID-19, adjusting to WFH can be a challenging exercise for a person with limited resources and no support. In India, not all the companies have WFH policy ready; many have just created it due to lockdown. There have been examples where no definite policy has been framed, and work has been expected from the employees in the same manner as in the case of office. This has created many issues for many professionals in terms of proper connectivity, designated personal space, time management, additional household responsibilities, limited guidance, and no peer communication. In the existing literature, there has been no concrete variable to measure all these difficulties. Thus, the researchers have attempted to quantify these as the operational difficulty variable and test their impact on job performance, distress, and life satisfaction during this pandemic time.

H7. Operational discomfort increases distress.

H8. Operational discomfort negatively affects job performance. 


\section{Distress}

The concept of psychological distress is widely employed in medical and social science research. It refers to an unpleasant emotional and psychological state that affects the individual's coping ability with a set of circumstances (Sellick and Edwardson 2007). Earlier studies on the epidemics like SARS, MERS, and Ebola disclosed the gravity of emotional distress observed in the general public and medical practitioners. The studies concluded the presence of posttraumatic stress disorder, depression, anxiety, fatigue, and breakdown for pre-epidemic, epidemic, and post epidemic periods (Lee et al. 2020). Although considerable attention has been given to academic stress in the research, job-related distress has been a neglected area (Beehr and Newman 1978). Most work distress studies have been conducted for a set of workers in a specific sector such as nurses (Bourbonnais et al. 2005), lawyers (Hopkins and Gardner 2012a), social workers (Kagan and Itzick 2019), and others. The results of these studies indicate a strong association between long work hours, high job demand, low social support at work, job insecurity, and psychological distress (Bourbonnais et al. 2005; Hopkins and Gardner 2012a). Further, psychological distress as a construct has extensively been measured using Kessler's K10 scale (Feng et al. 2018). A modified version of the Kessler scale with only 6 items is increasingly getting popular to measure distress. Recently, the K6 scale was used to measure psychological distress among Japanese female managers (Sugiura and Iwata 2016), Japanese emergency workers (Mafune et al. 2019), Chinese health professional students (Li et al. 2020), and Chinese dentists (Shacham et al. 2020) during COVID 19.

H9. Distress negatively affects life satisfaction.

H10. Distress negatively affects job performance.

\section{Job Performance}

Job performance is a function of the application of a person's abilities, skills, and aptitudes in the setting of a job in an organization (Hackman and Oldham 1976; Steers and Rhodes 1978). The performance is affected by the complexities of work and defined in various ways depending on the multiple phases and complications of the job (June and Mahmood 2011). Life event changes can affect the employee's work performance positively or adversely (Dennis 1956). In this paper, the researchers have measured job performance through work commitment and task competence. Employees' commitment to their work can have a direct link to their health and well-being. A strong commitment can make employees vulnerable to negative work-related stressors (Wersebe et al. 2018). However, work commitment is indispensable for employees' well-being, as employees with high commitment to their work are mostly in a positive state of excitement, happiness and feel energized to work hard (Wersebe et al. 2018). Employees with low commitment to work are more susceptible to psychological states of emotional distress and fatigue (Chordiya et al. 2017). Task competence refers to the proficiency with which an employee performs the delegated activities that are officially documented as part of their jobs (Borman and Motowidlo 1993). In simple terms, we can view competence as an accomplishment of duties and tasks stated in a job description (Murphy 1989). WFH is increasing workers' organizational commitment and job satisfaction, as it provides higher motivation (van der Lippe and Lippényi 2020). Since nobody is physically monitoring the employee, the individuals have greater discretion over how they can complete their tasks, thereby increasing task competence (Kossek and Thompson 2016).

H11. Good job performance enhances life satisfaction.

H12. The relationship between family distractions and life satisfaction is sequentially and positively mediated by distress and job performance.

H13. The relationship between lifestyle choice and life satisfaction is sequentially and positively mediated by distress and job performance.

H14. The relationship between role overload and life satisfaction is sequentially and negatively mediated by distress and job performance.

H15. The relationship between operational discomfort and life satisfaction is sequentially and negatively mediated by distress and job performance.

\section{Materials \& Methods}

The present study analyses the impact of COVID-19 induced changes in the lifestyle, work situations, overlapping responsibilities, and discomfort among the working professionals on their job performance, distress, and life satisfaction. This study has been conducted in the Delhi \& NCR region of India, between the third \& fourth phase of lockdown (data has been collected from 15th May - 22nd May). The study sample consisted of professionals residing in Delhi \& NCR and working in any private or public enterprise. The snowball sampling technique has been used to reach the respective sample. Due to the ongoing pandemic, this was the only possible way of data collection. The authors have first sent the questionnaires to their colleagues and peers and asked them to forward them to their colleagues, peers, and friends. The authors have asked for the opinion of prospective respondents through the various social media platforms as well. 


\section{Sample}

A total of 500 responses were received, and 433 were valid among them, as others were either unengaged or biased. The 10 times rule has been satisfied in our sample as the number of items in the model has been 36 , thus a minimum of 360 respondents to be required (Barclay et al. 1995). The sample size has also been confirmed with the G*Power. As suggested by it, to achieve the statistical power of $80 \%$ with an effect size of $15 \%$, at least 98 observations are needed, and it is advisable to have 3 times this number (Joe F. Hair et al. 2013).

\section{Measures}

The questionnaire survey has been used for the primary data collection. Since in-person questionnaires could not be gathered due to the ongoing pandemic, the authors have shared the questionnaire distribution among their contacts through emails, WhatsApp, and social media platforms. The first section of the questionnaire focused on collecting the respondents' demographics, i.e., age, gender, occupation, and status as a parent. The next section analyzed the COVID-19 specific knowledge among the respondents and changes in work hours before and during the pandemic. This is followed by the section analyzing the study's independent factors, i.e., lifestyle choices, family distraction, role overload, discomfort, and job performance. The fourth section is dedicated to collecting information on the level of distress experienced by them in the past weeks.

The constructs of role overload (RO), family distraction (FD), and lifestyle choices (LC) were measured on a fivepoint scale (Prasad et al. 2018). In the wake of the Covid-19 pandemic, authors have added a new construct to measure the challenges faced by working professionals due to the lockdown and WFH situation. A total of 10 items has been pretested on 50 respondents, and before that, these items have been validated by two academicians and three industry experts. The exploratory factor analysis has been conducted to ensure the construct's reliability, and the resulting factor has been named operational discomfort (OD) with seven items. The final items of the operational discomfort construct have been; namely, I have limited resources to work from home; I do not have designated workspace in the home; I face lack of guidance in work from home; I am not able to fully prioritize the work now; I have added family responsibility along with work, and I am having limited communication with my peers.

Job performance has been measured by way of two subitems, i.e., task competence and commitment adapted from the Taxonomy of higher-order performance dimensions model (Campbell et al. 1990). Only these two constructs could be related to the respondent's job performance in the pandemic; thus, not all the items of the model have been used. The K-6, i.e., Kessler 6 scale, has been adapted for measuring the distress among the respondents over the period of 4 weeks before the survey. It is the truncated version of the K-10 scale and can be used to analyze the levels of distress in troubled times like that of COVID-19 (R. Kessler et al. 2003). The dependent variable of life satisfaction (LS) has been adapted to measure one's satisfaction with life, based on five items measured on a seven-point scale (Diener et al. 1985).

\section{Pilot Study}

Since the model involved the formulated and modified constructs, exploratory factor analysis has been conducted on the data gathered from the pilot survey. All the factor loadings have been greater than 0.40 cut-off, and internal reliability, measured by Cronbach's alpha, has been greater than 0.70 (Joseph F Hair et al. 1998). To ensure survey questions are clear, concise and there is no potential common method bias, the Harman one factor test has been conducted. It has been found that variance does not exceed the cut-off value of 50\% (Harman 1976). Also, a full collinearity test was carried out (Kock \& Lynn, 2012). All variance inflation factors (VIF) values resulting from that test procedure were equal to or lower than 3.3, indicating that the model does not suffer from common method bias.

\section{Tools of Analysis}

The pilot survey has been conducted to confirm the face validity and content validity. The multiple logistic regression has been conducted to analyze the impact of categorical variables on the distress levels. Then an assessment of measurement and structural equation model has been conducted using Partial Least Squares Structural Equation Modeling (PLS-SEM) through SmartPLS 3.3.3. The bootstrapping technique has been done to test the significance of the hypotheses. To test the predictive ability of the model, the technique of blindfolding and PLS predict has also been adopted. As the study has multiple independent \& dependent relationships along with various mediation hypothesized relationships, SmartPLS has been used. Another reason for using SmartPLS is for testing the theoretical model from a predictive perspective (Hair et al. 2019).

\section{Results}

\section{Respondents' Demographic Profile}

The valid sample size used in the study was 433 participants of Delhi, India. The survey has $57 \%$ females and $43 \%$ males. An almost similar distribution of respondents in different age groups are found, with $35.10 \%$ in $30-44$ years followed by 
$33.90 \%$ and $30.90 \%$ in $20-29$ years and more than 45 years, respectively. The descriptive statistics have been presented in Annexure 1. Approximately 50\% of the respondents have been married, $43 \%$ have at least one child, while $57 \%$ do not have children. In terms of occupation, teachers and private employees represent $43.20 \%$ and $43.90 \%$ of the sample. The $33.50 \%$ and $35.60 \%$ of the respondents draw annual salary within the range of 5-10 lakhs and greater than 10 lakhs respectively, and approximately $61 \%$ said that they are getting their actual salary during the lockdown. Almost $40 \%$ of the working professionals have said that they are either getting less or no salary during the lockdown. In terms of pressure by the managers or superiors to work on weekends, only $26.10 \%$ said they are pressurized while $73.90 \%$ were not pressurized to work on weekends. Another alarming demographic characteristic about the study sample has been that approximately $62 \%$ of the respondents spend less than one hour on COVID-19 related information, while only $6 \%$ spend more than two hours on the same.

\section{Respondents' Demographic Profile in Relation to Levels of Distress}

The percentage of professional showing symptoms of distress have been somewhat similar in across age groups, with a little bit higher for the 20-29 years age group, while $57 \%$ of the respondents in more than 45 years age group have not been showing any distress (see Annexure 2). It has been observed that females (48\%) have been experiencing more distress than the males (41\%). Approximately $33 \%, 10 \%$, and $3 \%$ of the females have been showing signs of mild, moderate, and severe distress during the pandemic, respectively. Out of the $27 \%$ of the respondents who presume that returning to work during COVID-19 has been of severe threat have been experiencing more distress as compared to the respondents presuming a little bit or moderate threat. Most of the professionals have been experiencing mild distress in terms of perceived threat in joining the work amid ongoing pandemics. Out of the $33 \%$ of the professionals who spent 1-2 hours on the news related to the pandemic, $73 \%, 23 \% \& 5 \%$ have been under mild, moderate, and severe distress. Among the respondents who have adequate knowledge about the COVID-19, $53 \%$ have no symptoms of distress, while $47 \%$ have been experiencing distress. Out of $40 \%$ of the professionals who have not been getting full salary during the pandemic, $66 \%$ and $25 \%$ have been experiencing mild and moderate distress, respectively. $71 \%$ and $66 \%$ of the single and married professionals, respectively, have been showing symptoms of mild distress. However, in terms of severe distress, the percentage of married professionals have been more as compared to single and divorced professionals. Out of the $13 \%$ of the semi \& government professionals, $81 \%$ have been suffering from mild distress, while $43 \%$ and $44 \%$ of teachers and private employees, $73 \%$ and $62 \%$, are suffering from mild distress. $31 \%$ of the total private employees and $9 \%$ of the total teachers suffer from moderate to severe distress, respectively. Finally, $72 \%, 24 \%$, and $10 \%$ of the total of professionals in salary brackets of $>10$ lakhs, $5-10$ lakhs, and $<5$ lakhs respectively, have been showing symptoms of mild, moderate, and severe distress, respectively.

\section{The Impact of Demographic Variables on Overall Distress}

The multinomial logistic regression has also been carried to determine the categorical variables associated with the overall distress (score $>14$ ). The distress scores have been converted into dummy variables, with total scores on six items greater than 14 noted as 1 and rest as $0(1=$ score $>=14 ; 0=$ score $<14)$. This has been important in the analysis as it has highlighted, who are at high risk of distress and require care during this COVID-19 lockdown period. The results of the multinomial logistic regression have been given in Annexure 3. The professionals who have been pressurized to work on weekends during the present work from home scenario have $70.9 \%$ increased risk of distress (OR 1.709 [1.047-2.792]), while the respondents who been married were found to be 2.69 times more likely to have distress (OR 2.685 [1.202-6.006]). The respondents who have adequate knowledge about the COVID-19 were twice as likely to show symptoms of distress (OR 2.078 [1.091-3.960]). However, working hours during the lockdown, occupation, annual salary, and having a child has not been significant indicators of the distress. Another alarming association has been seen between perceived threat in joining the office back during the pandemic and the distress. The professionals who think that threat to join the office has been of serious concern were 3.4 times more likely (OR 3.393 [1.261-9.127]) to show distress as compared to those who think there is a little bit risk (OR 2.720[0.959-7.713]).

\section{Measurement Model Assessment}

The first measurement model needs to be tested for item reliability, construct reliability, discriminant validity, and convergent validity to ensure a satisfactory model to proceed to the path analysis. Table 1 shows the factor loadings (item reliability), Cronbach alpha $(\alpha)$, and average variance explained (AVE). As per the threshold level, the factor loadings greater than equal to 0.708 have been considered reliable (Joe F. Hair et al. 2013). The composite reliability (CR) and Cronbach alpha values should be higher than 0.70; however, they should be less than 0.95 . Convergent validity is confirmed with AVE exceeding the threshold of 0.5 (Sarstedt et al. 2017). The results show that most of the factor loadings in our model have been higher than 0.708 . 
Table 1 Convergent Validity Results

\begin{tabular}{|c|c|c|c|c|c|}
\hline Construct & Items & Loadings & $\begin{array}{l}\text { Cronbach's } \\
\text { Alpha }(\alpha)\end{array}$ & $\begin{array}{l}\text { Composite } \\
\text { reliability (CR) }\end{array}$ & $\begin{array}{l}\text { Average variance } \\
\text { extracted (AVE) }\end{array}$ \\
\hline \multirow[t]{4}{*}{ Role Overload (RO) } & RO1 & 0.696 & \multirow[t]{4}{*}{0.734} & \multirow[t]{4}{*}{0.832} & \multirow[t]{4}{*}{0.554} \\
\hline & $\mathrm{RO} 2$ & 0.741 & & & \\
\hline & $\mathrm{RO} 3$ & 0.767 & & & \\
\hline & $\mathrm{RO} 4$ & 0.770 & & & \\
\hline \multirow[t]{4}{*}{ Lifestyle Choices (LC) } & $\mathrm{LC} 1$ & 0.776 & \multirow[t]{4}{*}{0.786} & \multirow[t]{4}{*}{0.861} & \multirow[t]{4}{*}{0.608} \\
\hline & $\mathrm{LC} 2$ & 0.817 & & & \\
\hline & LC3 & 0.763 & & & \\
\hline & $\mathrm{LC} 4$ & 0.760 & & & \\
\hline \multirow[t]{4}{*}{ Family Distraction (FD) } & FD1 & 0.872 & \multirow[t]{4}{*}{0.815} & \multirow[t]{4}{*}{0.878} & \multirow[t]{4}{*}{0.645} \\
\hline & FD2 & 0.799 & & & \\
\hline & FD3 & 0.816 & & & \\
\hline & FD4 & 0.718 & & & \\
\hline \multirow[t]{7}{*}{ Occupational Discomfort (OD) } & OD1 & 0.759 & \multirow[t]{7}{*}{0.887} & \multirow[t]{7}{*}{0.912} & \multirow[t]{7}{*}{0.597} \\
\hline & OD2 & 0.774 & & & \\
\hline & OD3 & 0.788 & & & \\
\hline & OD4 & 0.751 & & & \\
\hline & OD5 & 0.708 & & & \\
\hline & OD6 & 0.850 & & & \\
\hline & OD7 & 0.772 & & & \\
\hline \multirow[t]{6}{*}{ Job Performance (JP) } & JP1 & 0.736 & \multirow[t]{6}{*}{0.859} & \multirow[t]{6}{*}{0.895} & \multirow[t]{6}{*}{0.586} \\
\hline & JP2 & 0.712 & & & \\
\hline & JP3 & 0.754 & & & \\
\hline & JP4 & 0.784 & & & \\
\hline & JP5 & 0.823 & & & \\
\hline & JP6 & 0.780 & & & \\
\hline \multirow[t]{6}{*}{ Distress (DS) } & DS1 & 0.673 & \multirow[t]{6}{*}{0.821} & \multirow[t]{6}{*}{0.870} & \multirow[t]{6}{*}{0.529} \\
\hline & DS2 & 0.732 & & & \\
\hline & DS3 & 0.769 & & & \\
\hline & DS4 & 0.671 & & & \\
\hline & DS5 & 0.831 & & & \\
\hline & DS6 & 0.671 & & & \\
\hline
\end{tabular}

However, there are items with lower factor loadings; still, they have been retained in the model as the construct had reliability, convergent validity, and discriminant validity. The CR and AVE values have been higher than the threshold values suggested.

The discriminant validity has been assessed using Heterotrait - Monotrait ratio (HTMT). Table 2 shows all the values have been less than 0.85 (Sarstedt et al. 2017). Hence, indicating that the measurement model has discriminant validity and that the constructs in the measurement model were all distinct from each other.

\section{Structural Model Assessment}

In terms of assessing the structural model, collinearity between the constructs should also be checked. The VIF value equal to or greater than 5 is considered as the presence of multi-collinearity in the constructs. In our model, all the VIF values have been less than five, indicating no multicollinearity problem (see Annexure 4). The model has been then tested for explanation power $\left(R^{2}\right)$ and predictive relevance $\left(Q^{2}\right)$. As a thumb rule, the $\mathrm{R}^{2}$ value of $0.25,0.5$, and 0.7 are described as

Table 2 Discriminant Validity Results

\begin{tabular}{lllllll}
\hline & DS & FD & JP & LC & RO & OD \\
\hline DS & & & & & \\
FD & 0.733 & & & & \\
JP & 0.621 & 0.527 & & & \\
LC & 0.664 & 0.640 & 0.499 & & \\
RO & 0.777 & 0.583 & 0.479 & 0.691 & \\
OD & 0.556 & 0.489 & 0.500 & 0.508 & 0.465 \\
\hline
\end{tabular}


weak, moderate, and strong explanation power. While the threshold value of $\mathrm{Q}^{2}$, higher than $0,0.25$, and 0.50 , depict the small, medium, and large predictive relevance of the PLSpath model (Joseph F. Hair et al. 2019). In the present study, FD, LC, RO, and OD jointly explain $35.8 \% \& 54.2 \%$ of the variance in the job performance and distress, respectively. Thus, indicating weak to moderate explanation power. The job performance and distress were able to explain $32.4 \%$ of the variance in life satisfaction during COVID-19. Figure 1 shows the structural model of the study.

In terms of the structural path analysis, Table 3 shows the beta coefficients and the $p$ values. Operational discomfort, family distractions, and distress have a significant negative effect on job performance. In contrast, role overload and lifestyle choices do not have a significant effect on job performance. As the distress level increases, it adversely affects the job performance of the employee with $\beta=-0.303, p<0.01$. Neither the change in lifestyle choices improve or worsens the job performance, nor does the change in role overload. Hence, only $\mathrm{H}_{2}$ and $\mathrm{H}_{6}$ have not been supported by the results of the study, while $\mathrm{H}_{4}, \mathrm{H}_{8}$, and $\mathrm{H}_{10}$ have been supported. In terms of effect on the distress experienced by the respondents, role overload $(\beta=0.337$, $p<0.01)$, operational discomfort $(\beta=0.161, \mathrm{p}<0.01)$ and $\mathrm{LC}$ $(\beta=-0.144, p<0.01)$ had a significant effect. Thus, as the role overloading increases, family involvement increases, and the operational difficulty increases, leading to an increase in distress levels. However, as lifestyle choices improve, the distress level reduces. Hence, $\mathrm{H}_{1}, \mathrm{H}_{5}$, and $\mathrm{H}_{7}$ have been supported by the results of the study. The effect of distress has been more on life satisfaction, as compared to job performance, during the pandemic as the $\mathrm{f}^{2}$ of the former was 0.238 , and the latter was 0.069 .

The techniques of blindfolding have been conducted to assess the predictive relevance of the model. The results highlight $20 \%, 27.9 \%$, and $22 \%$ medium predictive accuracy in job performance, distress, and life satisfaction, respectively, as the value lies in the range of $0.15-0.30$. Also, predictive relevance has been analyzed using the PLS predict with 10 folds and seven repetitions. It helps in analyzing the predictive ability of the endogenous variables through the indicators in the reflective measurement model. Annexure 5 depicts the difference between RMSE values of PLS-SEM and naive benchmark, i.e., the LM model. Since all the $\mathrm{Q}^{2}$ values have been greater than zero and RMSE of the PLS-SEM model have been less, i.e., it generates lower errors for all the indications; thus, the model has predictive relevance. This model can be used to predict job performance, distress, and life satisfaction sufficiently well.

\section{Mediation Results}

Using the technique of bootstrapping, the model has been tested for the presence of serial mediation. The results presented in Table 4, highlights the significance of four serial mediated paths. The indirect effect of lifestyle choices on life satisfaction sequentially mediated by distress and job performance is not statistically significant $(\mathrm{b}=0.007, p=0.054$; confidence interval has value zero included), so distress and job performance do not jointly mediate the relationship between lifestyle choice and

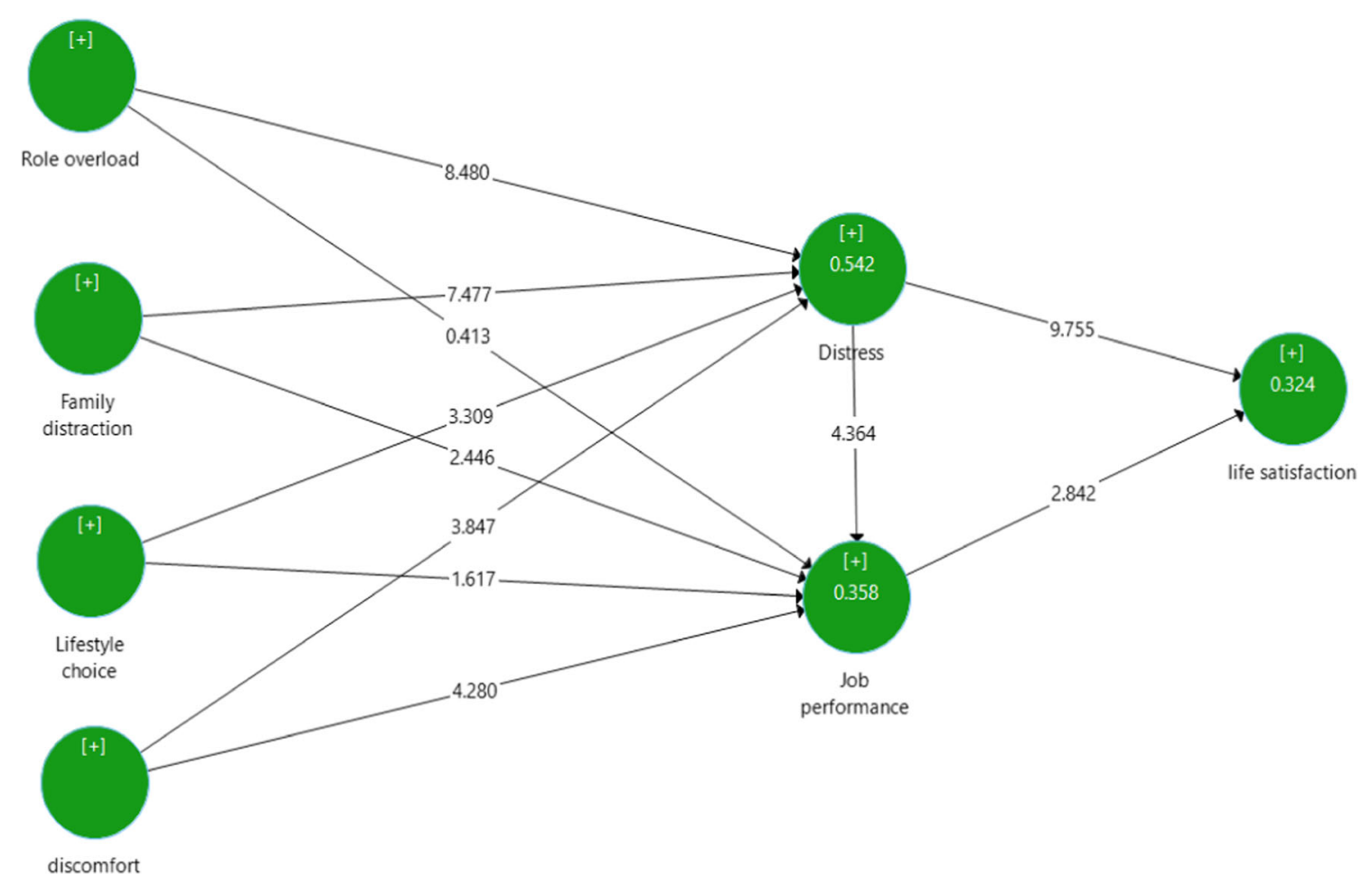

Fig. 1 Structural Model 
Table 3 Hypothesis testing results

\begin{tabular}{|c|c|c|c|c|c|c|}
\hline Hypothesis & Relationships & $\beta$ & $\mathrm{p}$ - values & $\mathrm{f}^{2}$ & LLCI $(5 \%)$ & ULCI (95\%) \\
\hline H1 & $\mathrm{LC}->\mathrm{DS}$ & -0.144 & $0.001 *$ & 0.03 & -0.212 & -0.07 \\
\hline $\mathrm{H} 2$ & $\mathrm{LC}->\mathrm{JP}$ & 0.089 & 0.106 & 0.01 & -0.002 & 0.178 \\
\hline H3 & $\mathrm{FD}->\mathrm{DS}$ & 0.299 & $0.000 *$ & 0.131 & 0.231 & 0.363 \\
\hline $\mathrm{H} 4$ & FD ->JP & -0.135 & $0.014^{*}$ & 0.019 & -0.226 & -0.044 \\
\hline H5 & $\mathrm{RO}->\mathrm{DS}$ & 0.337 & $0.000 *$ & 0.167 & 0.266 & 0.399 \\
\hline H6 & $\mathrm{RO}->\mathrm{JP}$ & -0.022 & 0.679 & 0.003 & -0.069 & 0.11 \\
\hline $\mathrm{H} 7$ & $\mathrm{OD}->\mathrm{DS}$ & 0.161 & $0.000 *$ & 0.045 & 0.093 & 0.232 \\
\hline $\mathrm{H} 8$ & OD ->JP & -0.195 & $0.000 *$ & 0.046 & -0.272 & -0.122 \\
\hline H9 & DS $->$ LS & -0.463 & $0.000 *$ & 0.238 & -0.532 & -0.376 \\
\hline H10 & DS ->JP & -0.303 & $0.000 *$ & 0.069 & -0.418 & -0.187 \\
\hline H11 & $\mathrm{JP}->\mathrm{LS}$ & 0.166 & $0.005^{*}$ & 0.034 & 0.065 & 0.257 \\
\hline
\end{tabular}

*is significant at $5 \%$ level of significance life satisfaction. The proposed H13 was not supported. Also, with respect to H15, distress \& job performance do not sequentially mediate the relationship between operational discomfort and life satisfaction. The indirect effect of family distractions \& life satisfaction serially mediated through distress and job performance is significant and direct effect of family distractions to life satisfaction is also significant, thus showing the presence of partial mediation. Hence, we fail to reject H12, i.e., the indirect effect of family distractions on life satisfaction is sequentially mediated by distress \& job performance. In terms of the indirect effect of role overload on life satisfaction, only the indirect effect through distress and job performance has been significant, while the direct effect is significant at 5\% level of significance. Thus, the presence of full mediation is indicated in between role overload and life satisfaction through distress \& job performance. Hence, H14 is supported by the results, i.e., distress and job performance serially mediates the relationship between role overload and life satisfaction.

\section{Discussion}

COVID-19 has not only abruptly toppled normal work routines, it has also accelerated trends that were already underway involving the migration of workers to the online or virtual

Table 4 Mediation Results

\begin{tabular}{llll}
\hline Relationships & Direct effect & Indirect Effect & Result \\
\hline FD ->DS -> JP -> LS & $0.161^{*}$ & $0.015^{*}$ & Partial mediation \\
LC ->DS -> JP -> LS & 0.081 & 0.007 & No mediation \\
RO ->DS -> JP ->LS & $-\mathbf{0 . 1 6}$ & $-0.017^{*}$ & Full mediation \\
OD ->DS -> JP -> LS & $-0.107^{*}$ & -0.008 & No mediation \\
\hline
\end{tabular}

*is significant at $5 \%$ level of significance mode. The pandemic has been instrumental in making a shift from the physical work set up to work from home set up. This major shift, along with the widespread pandemic, can affect employee's job performance and can induce psychological distress among them. This has also been verified by the recent survey of UK healthcare workers, where the results stated that women are experiencing distress and job disruption due to the Covid-19 pandemic (Institute for Public Policy Research 2020). Therefore, this change has been studied with the help of lifestyle choices, role overload, family distractions, operational difficulty, and their influence on job performance, distress, and life satisfaction. Thus, the paper attempted to study the impact of COVID-19 induced factors on the working population's life satisfaction.

The study results have been based on a sample of 433 respondents (Annexure 5), which comprised 57\% females and $43 \%$ males belonging to different age-group levels. Measuring the distress levels using the K-6 scale, it has been found that $30.9 \%$ and $14.5 \%$ of the participants felt nervous some of the time and most to all the time, respectively, during the lockdown. This might be because of the discomfort that they have been facing due to the WFH pressure along with managing the domestic responsibilities. More than $70 \%$ of participants have completely agreed that they would expect operational safety practices to be followed at their workplaces once it becomes fully operational. The respondents themselves would also follow the guidelines like washing hands and wearing masks most of the time. The percentage of professionals showing distress symptoms has been somewhat similar across all age groups, with a little bit higher for the 20-29 years age group, while $57 \%$ of the respondents in the more than 45 years age group have not been showing any distress. It has been observed that females (48\%) have been experiencing more distress as compared to the males (41\%). Approximately $33 \%, 10 \%$, and $3 \%$ of the females have been showing signs of mild, moderate, and severe distress during 
the pandemic, respectively. Out of the $27 \%$ of the respondents who presume that returning to work during COVID-19 has been a serious threat, they have been experiencing more distress than the respondents presuming a little bit or moderate threat. Most of the professionals have been experiencing mild distress in terms of perceived threat in joining the work amid ongoing pandemics. Out of the $33 \%$ of the professionals who spent $1-2 \mathrm{~h}$ on the news related to the pandemic, $73 \%, 23 \% \&$ $5 \%$ have been under mild, moderate, and severe distress. Among the respondents who have adequate knowledge about the COVID-19, 53\% have no symptoms of distress, while $47 \%$ have been experiencing distress. Out of $40 \%$ of the professionals who have not been getting full salary during the pandemic, $66 \%$ and $25 \%$ have been experiencing mild and moderate distress, respectively. The $71 \%$ and $66 \%$ of the single and married professionals, respectively, have been showing symptoms of mild distress. However, in terms of severe distress, the percentage of married professionals have been more as compared to single and divorced professionals. Out of the $13 \%$ of the semi \& government professionals, $81 \%$ have been suffering from mild distress, while of $43 \%$ and $44 \%$ of teachers and private employees, $73 \%$ and $62 \%$ have been found to be suffering from mild distress, respectively. $31 \%$ of the total private employees and $9 \%$ of the total teachers have been found to be suffering from moderate to severe distress, respectively. Finally, $72 \%, 24 \%$, and $10 \%$ of the total of professionals in salary brackets of $>10$ lakhs, 5-10 lakhs, and $<$ 5lakhs respectively, have been showing symptoms of mild, moderate, and severe distress, respectively.

The results of multinomial logistic regression found that the professionals who have been married and have increased workload due to COVID-19 experience a high risk of distress. These empirical results are in harmony with the results of previous researches where authors have stated that when an individual actively participates in one role, he feels distracted by the thoughts and demands of the other role (Ashforth et al. 2000; Frone et al. 1992) which may add to the distress levels. Thus, considering the role theory as discussed in the theoretical background, we can observe that managing family and work responsibilities and that too with additional workload becomes very difficult for an employee to manage (Greenhaus and Beutell 1985; Levinson et al. 1965). One's inability to meet the expectations leads to demotivation and distress. Further, the threat of returning to the office during and post-COVID-19 has been evident in the study.

In the first set of hypotheses ( $\mathrm{H} 1$ and $\mathrm{H} 2$ ), it was anticipated that good life choices would reduce stress and enhance the job performance of an individual. Our results found that good life choices significantly reduce the stress; however, it fails to improve the job performance. Confirming the past studies (Fried 2017; Gariepy et al. 2010; Hamer et al. 2009; Prasad et al. 2016), it was found that practicing good lifestyle choices in eating habits, alcoholism, and sleeping pattern helps to decrease distress levels. However, our results could not find any relationship between life choices and job performance.

Second, our results confirm the second set of hypotheses (H3 and H4). It was predicted that increased family distractions would increase distress and will impact job performance negatively. Amidst the lockdown, when every employee was forced to work from home, that too, without any support of house help, schools, and day-care facilities, the veil between personal and professional lives disappeared. Therefore, the employee not only suffered from distress (Prasad and Vaidya 2020), s/he could not contribute to the job productively. The results confirm the Spillover theory (Williams and Alliger 1994).

Our third set of hypotheses (H5 and H6) predicted that role overload would increase distress and affect job performance negatively. Our results confirm H5; however, they fail to accept H6. Supporting the past studies (Kahn 1980; Marini et al. 1995), it is found that increased work expectations and pressure results in anger, frustration, and stress among the working segment.

Social distancing norms amid the covid era forced the organizations to shift the work from physical space to the employees' homes. The sudden introduction of WFH left employees' all over the world startled. Not all organizations had the ways and means to support WFH of each employee; therefore, employees faced operational discomfort. In H7 and $\mathrm{H} 8$, it was predicted that operational discomfort would increase distress levels among employees and will be negatively contributing to job performance. The results of this study confirm the same. The next two hypotheses H9 and H10, anticipated that the distress would negatively affect life satisfaction and job performance. Consistent with the past literature (Hopkins and Gardner 2012b; Kagan and Itzick 2019), the results confirm that as distress levels increase, one's job performance is affected while satisfaction with life is ultimately diminished.

Further, it was predicted in $\mathrm{H} 11$ that good job performance enhances life satisfaction. The results confirm that when an employee's job performance is improved, as a result of heightened work commitment (Wersebe et al. 2018) and task competence (Borman and Motowidlo 1993; Murphy 1989), it enhances one's life satisfaction. Finally, hypothesis H12, H13, H14 \& H15 assumed that the relationship of family distractions, lifestyle choice, role overload \& operational discomfort with life satisfaction respectively is sequentially and positively mediated by distress and job performance, which was tested through the bootstrapping technique. The findings of the study observed the indirect effect of family distraction on life satisfaction is sequentially mediated by distress \& job performance. Also, the results of the study supported H14, stating that distress and job performance serially mediate the relationship between role overload 
and life satisfaction. However, the findings of the study did not support H13 \& H15.

Amid the COVID-19, adjusting to WFH can be a strenuous exercise. The findings of the previous studies state that crossrole disturbances and regular commotions, thereby escalating difficulties of meeting work and family requirements (Chen et al. 2009). The empirical results of this study also state that family distraction and operational discomfort have a significant and negative effect on job performance, unlike lifestyle choices and role overload, which had no significant impact. Rather than having a direct impact on distress levels, the impact of family distractions on job performance is more evident. Trying to finish work amidst gleeful young children running around the house is a scenario that many WFH employees can identify with. Such situations significantly affect one's work quality, and as a result, job performance suffers.

Further, role overload, lifestyle choices have been found to significantly affect employees' distress levels. Thus, it proves that as work roles demand more from an employee, the time for oneself gets reduced; consequently, the person experiences high levels of distress and anxiety. However, practicing good lifestyle choices in eating habits, alcoholism, sleeping patterns, and other health-related regimes helps decrease distress levels. As observed by researchers (Prasad et al. 2016), healthy lifestyle choices lead to an increase in an individual's resistance to stress and vice-versa. This may explain why the impact of lifestyle choices on distress levels is much more evident on distress compared to job performance. The same goes for role overload. Wearing too many hats at home (i.e., employee, parent, spouse, daughter/son) can be daunting, which significantly adds to one's distress rather than directly impacting job performance. Also, a study (Kahn 1980) has found that increased work expectations and pressure leads to anger, frustration, and stress. Similarly, the operational discomfort is significantly impacting distress as well as job satisfaction. In sum, as distress levels increase, one's job performance is affected while satisfaction with life is ultimately diminished. In contrast, if one's job performance is improved as a result of heightened work commitment and task competence, this will enhance one's life satisfaction.

\section{Limitation of the Study}

Although the present study has important and substantial implications, it is not free from limitations. As physical contact was not possible for the collection of data, the authors have used non-probability sampling to gather the survey participants. A limited number of demographics have been taken in the present study. However, analyzing the effect of others can add more content to the existing literature and ensure broader population coverage. The study has been conducted only on the sample of working professionals residing in Delhi \& NCR, India. Thus, by expanding this study to pan India, the researchers can ensure a better viewpoint on the existing distress levels among the population owning the continuation of the COVID-19 pandemic.

\section{Conclusion}

COVID-19 has phenomenally changed the workspace landscape. Most of the organizations have been forced to shift from a physical office to WFH set up. This shift coupled with the ongoing pandemic can affect the individual employee's job performance, which in turn can induce psychological distress. With this primary objective, this paper studied the impact of COVID19 induced factors on the life satisfaction of employees. Using 433 survey responses, multinomial logistic regression, and PLS analysis, it was found that positive life choices, role overload, and operational discomfort affect employee's distress significantly. The job performance of the employees is adversely affected by factors like family distraction, operational discomfort, and distress. Consistent with the role theory, it is observed that the increase in work commitments lead to distress among employees while distractions from family members disrupt the quality of work. While good job performance contributes to life satisfaction, distress significantly diminished it. In closing, this paper has contributed insights onto how life satisfaction can be affected by work performance and distress caused by Covid-19 stressors. This paves the way for more studies to be done on work-life balance under WFH arrangements for as long as the pandemic of Covid-19 is prevalent.

Supplementary Information The online version contains supplementary material available at https://doi.org/10.1007/s12144-021-01567-0.

Acknowledgements We would like to acknowledge the guidance provided by Dr. Marko Sarstedt, Otto-von-Guericke-University, Magdeburg, Germany for critically reviewing our study. His critical reviews have helped us in enriching the present study.

Availability of Data and Material Not Applicable.

Author Contribution Dr. Parul Kumar: Conceptualization, Formal analysis, Editing, Investigation, Methodology.

Dr. Neha Kumar: Conceptualization, Methodology, Writing - original draft.

Dr. Priti Aggarwal: Conceptualization, Writing - original draft, Editing.

Dr. Jasmine A.L. Yeap: Conceptualization, Methodology, Proof reading, Finalization of draft.

Funding The authors did not receive support from any organization for the submitted work. 
Code Availability Not Applicable

\section{Declarations}

Conflict of Interest On behalf of all authors, the corresponding author states that there is no conflict of interest.

Conflicts of Interest/Competing Interests All authors certify that they have no affiliations with or involvement in any organization or entity with any financial interest or non-financial interest in the subject matter or materials discussed in this manuscript.

\section{References}

Abdel-Hadi, A. (2012). Culture, quality of life, globalization and beyond. Procedia - Social and Behavioral Sciences, 50, 11-19. https://doi. org/10.1016/j.sbspro.2012.08.011.

Adams, G. A., King, L. A., \& King, D. W. (1996). Relationships of job and family involvement, family social support, and work-family conflict with job and life satisfaction. Journal of Applied Psychology, 81(4), 411-420. https://doi.org/10.1037/0021-9010. 81.4.411.

Ashforth, B. E., Kreiner, G. E., \& Fugate, M. (2000). All in a day's work: Boundaries and micro role transitions. The Academy of Management Review, 25(3), 472-491. https://doi.org/10.2307/259305.

Bacharach, S. B., Bamberger, P., \& Conley, S. C. (1990). Work processes, role conflict, and role overload: The case of nurses and engineers in the public sector. Work and Occupations, 17(2), 199-228. https:// doi.org/10.1177/0730888490017002004.

Barclay, D., Thompson, R., \& dan Higgins, C. (1995). The partial least squares (PLS) approach to causal modeling: Personal computer adoption and use an illustration. Technology Studies, 2(2), 285 309. https://doi.org/10.1017/CBO9781107415324.004.

Becker, G. S. (1965). A theory of the allocation of time. The Economic Journal, 75(299), 493-517. https://doi.org/10.2307/2228949.

Beehr, T. A., \& Newman, J. E. (1978). Job stress, employee health, and organizational effectiveness: A facet analysis, model, and literature review. Personnel Psychology, 31(4), 665-699. https://doi.org/10. 1111/j.1744-6570.1978.tb02118.x.

Bhagat, R. S. (1983). Effects of stressful life events on individual performance effectiveness and work adjustment processes within organizational settings: A research model. Academy of Management Review, 8(4), 660-671. https://doi.org/10.5465/amr.1983.4284672.

Biddle, S. J. H., \& Asare, M. (2011). Physical activity and mental health in children and adolescents: A review of reviews. British Journal of Sports Medicine, 45(11), 886-895. https://doi.org/10.1136/bjsports2011-090185

Borman, W. C., \& Motowidlo, S. J. (1993). Expanding the criterion domain to include elements of contextual performance. In Personnel Selection in Organizations (pp. 71-98).

Bourbonnais, R., Brisson, C., Malenfant, R., \& Vézina, M. (2005). Health care restructuring, work environment, and health of nurses. American Journal of Industrial Medicine, 47(1), 54-64. https:// doi.org/10.1002/ajim.20104.

ten Brummelhuis, L. L., \& Bakker, A. B. (2012). A resource perspective on the work-home interface: The work-home resources model. American Psychologist, 67(7), 545-556. https://doi.org/10.1037/ a0027974.

Campbell, C. H., Ford, P., Rumsey, M. G., Pulakos, E. D., Borman, W. C., Felker, D. B., De Vera, M. V., \& Riefelhaupt, B. J. (1990). Development of multiple job performance measures in a representative sample of jobs. Personnel Psychology, 43(2), 277300. https://doi.org/10.1111/j.1744-6570.1990.tb01559.x.

Caplan, R. D., Cobb, S., French, J. R. P., Harrison, R. V., \& Pinneau, S. R. (1975). Job demands and worker health. The National Institute for Occupational Safety and Health (NIOSH) Publications. https:// ntrl.ntis.gov/NTRL/dashboard/searchResults/titleDetail/PB276809. $\mathrm{xhtml}$

Chen, Z., Powell, G. N., \& Greenhaus, J. H. (2009). Work-to-family conflict, positive spillover, and boundary management: A personenvironment fit approach. Journal of Vocational Behavior, 74(1), 82-93. https://doi.org/10.1016/j.jvb.2008.10.009.

Chew, N. W. S., Lee, G. K. H., Tan, B. Y. Q., Jing, M., Goh, Y., Ngiam, N. J. H., Yeo, L. L. L., Ahmad, A., Ahmed Khan, F., Napolean Shanmugam, G., Sharma, A. K., Komalkumar, R. N., Meenakshi, P. V., Shah, K., Patel, B., Chan, B. P. L., Sunny, S., Chandra, B., Ong, J. J. Y., Paliwal, P. R., Wong, L. Y. H., Sagayanathan, R., Chen, J. T., Ying Ng, A. Y., Teoh, H. L., Tsivgoulis, G., Ho, C. S., Ho, R. C., \& Sharma, V. K. (2020). A multinational, multicentre study on the psychological outcomes and associated physical symptoms amongst healthcare workers during COVID-19 outbreak. Brain, Behavior, and Immunity., 88, 559-565. https://doi.org/10. 1016/j.bbi.2020.04.049.

Chordiya, R., Sabharwal, M., \& Goodman, D. (2017). Affective organizational commitment and job satisfaction: A cross-National Comparative Study. Public Administration, 95(1), 178-195. https://doi.org/10.1111/padm.12306.

Cobos-Sanchiz, D., Del-Pino-Espejo, M.-J., Sanchez-Tovar, L., \& Matud, M. P. (2020). The importance of work-related events and changes in psychological distress and life satisfaction amongst young Workers in Spain: A gender analysis. International Journal of Environmental Research and Public Health, 17(3), 1-14.

Colligan, T. W., \& Higgins, E. M. (2006). Workplace stress: Etiology and consequences. Journal of Workplace Behavioral Health, 21(2), 89 97. https://doi.org/10.1300/J490v21n02 07.

Crosbie, T., \& Moore, J. (2004). Work-life balance and working from home. Social Policy and Society, 3(3), 223-233. https://doi.org/10. 1017/s1474746404001733.

Daniels, D. A. K. (2000). Managing telework: Perspectives from human resource management and work psychology. $R \& D$ Enterprise: Asia Pacific, 3(4), 37-38. https://doi.org/10.1080/14401266.2000. 11001122.

Dennis, N. (1956). Coal is our life: An analysis of a Yorkshire mining community (Vol. 50). Eyre \& Spottiswoode.

Diener, E., Emmons, R. A., Larsem, R. J., \& Griffin, S. (1985). The satisfaction with life scale. Journal of Personality Assessment, 49(1), 71-75. https://doi.org/10.1207/s15327752jpa4901_13.

Diener, E., \& Seligman, M. E. P. (2002). Very happy people. Psychological Science, 13(1), 81-84. https://doi.org/10.1111/14679280.00415 .

Enshassi, A., Al Swaity, E., \& Arain, F. (2016). Investigating common causes of burnout in the construction industry. International Journal of Construction Project Management, 8(1), 43-56.

Extremera, N., Durán, A., \& Rey, L. (2009). The moderating effect of trait meta-mood and perceived stress on life satisfaction. Personality and Individual Differences, 47(2), 116-121. https://doi.org/10. 1016/j.paid.2009.02.007.

Fang, Y. Y., Huang, C. Y., \& Hsu, M. C. (2019). Effectiveness of a physical activity program on weight, physical fitness, occupational stress, job satisfaction and quality of life of overweight employees in high-tech industries: A randomized controlled study. International Journal of Occupational Safety and Ergonomics, 25(4), 621-629. https://doi.org/10.1080/10803548.2018.1438839.

Feng, D., Su, S., Wang, L., \& Liu, F. (2018). The protective role of selfesteem, perceived social support and job satisfaction against psychological distress among Chinese nurses. Journal of Nursing Management, 26(4), 366-372. https://doi.org/10.1111/jonm.12523. 
Fox, M. L., \& Dwyer, D. J. (1999). An investigation of the effects of time and involvement in the relationship between stressors and workfamily conflict. Journal of Occupational Health Psychology, 4(2), 164-174. https://doi.org/10.1037/1076-8998.4.2.164.

Fried, E. I. (2017). The 52 symptoms of major depression: Lack of content overlap among seven common depression scales. Journal of Affective Disorders, 208, 191-197. https://doi.org/10.1016/j.jad. 2016.10.019.

Frone, M. R., Russell, M., \& Cooper, M. L. (1991). Relationship of work and family stressors to psychological distress: The independent moderating influence of social support, mastery, active coping, and self-focused attention. Journal of Social Behavior \& Personality, 6(7).

Frone, M. R., Russell, M., \& Cooper, M. L. (1992). Antecedents and outcomes of work-family conflict: Testing a model of the workfamily Interface. Journal of Applied Psychology, 77(1), 65-78. https://doi.org/10.1037/0021-9010.77.1.65.

Gariepy, G., Nitka, D., \& Schmitz, N. (2010). The association between obesity and anxiety disorders in the population: A systematic review and meta-analysis. In International Journal of Obesity (Vol. 34, issue 3). https://doi.org/10.1038/ijo.2009.252.

Gautam, R., \& Sharma, M. (2020). Brain , Behavior , and Immunity 2019-nCoV pandemic: A disruptive and stressful atmosphere for Indian academic fraternity. Brain Behavior and Immunity, April, 1-2. https://doi.org/10.1016/j.bbi.2020.04.025.

Glenn, N. D., \& Weaver, C. N. (1981). The contribution of marital happiness to global happiness. Journal of Marriage and the Family, 43(1), 161. https://doi.org/10.2307/351426.

Goode, W. J. (1960). A theory of role strain. American Sociological Review, 25(4), 483. https://doi.org/10.2307/2092933.

Greenhaus, J. H., \& Beutell, N. J. (1985). Sources of conflict between work and family roles. Academy of Management Review, 10(1), 7688. https://doi.org/10.5465/amr.1985.4277352.

Greenhaus, J. H., Collins, K. M., Singh, R., \& Parasuraman, S. (1997). Work and family influences on departure from public accounting. Journal of Vocational Behavior, 50(2), 249-270. https://doi.org/10. 1006/jvbe.1996.1578.

Greenhaus, J. H., \& Powell, G. N. (2006). When work and family are allies: A theory of work-family enrichment. In Academy of Management Review (Vol. 31, issue 1). https://doi.org/10.2307/ 20159186.

Gutek, B. A., Searle, S., \& Klepa, L. (1991). Rational versus gender role explanations for work-family conflict. Journal of Applied Psychology, 76(4), 560-568. https://doi.org/10.1037/0021-9010. 76.4.560

Hackman, J. R., \& Oldham, G. R. (1976). Motivation through the design of work: Test of a theory. Organizational Behavior and Human Performance, 16(2), 250-279. https://doi.org/10.1016/00305073(76)90016-7.

Hair, Joe F., Hult, G. T. M., Ringle, C. M., \& Sarstedt, M. (2013). A Primer on Partial Least Squares Structural Equation Modeling (PLSSEM). In Sage.

Hair, J. F., Risher, J. J., Sarstedt, M., \& Ringle, C. M. (2019). When to use and how to report the results of PLS-SEM. European Business Review, 31(1), 2-24. https://doi.org/10.1108/EBR-11-2018-0203.

Hair, Joseph F, Black, W. C., Babin, B. J., Anderson, R. E., \& Saddle River Boston Columbus San Francisco New York Indianapolis London Toronto Sydney Singapore Tokyo Montreal Dubai Madrid Hong Kong Mexico City Munich Paris Amsterdam Cape Town, U. (1998). Multivariate Data Analysis a Global Perspective.

Halbesleben, J. R. B., Harvey, J., \& Bolino, M. C. (2009). Too engaged? A conservation of resources view of the relationship between work engagement and work interference with family. Journal of Applied Psychology, 94(6), 1452-1465. https://doi.org/10.1037/a0017595.
Hamarat, E., Thompson, D., Zabrucky, K. M., Steele, D., Matheny, K. B., \& Aysan, F. (2001). Perceived stress and coping resource availability as predictors of life satisfaction in young, middle-aged, and older adults. Experimental Aging Research, 27(2), 181-196. https://doi. org/10.1080/036107301750074051.

Hamer, M., Stamatakis, E., \& Steptoe, A. (2009). Dose-response relationship between physical activity and mental health: The Scottish health survey. British Journal of Sports Medicine, 43(14), 11111114. https://doi.org/10.1136/bjsm.2008.046243.

Harman, H. (1976). Modern factor analysis.

Hassard, J., Teoh, K. R. H., Visockaite, G., Dewe, P., \& Cox, T. (2018). The cost of work-related stress to society: A systematic review. Journal of Occupational Health Psychology, 23(1), 1-17. https:// doi.org/10.1037/ocp0000069.

Hawryluck, L., Gold, W. L., Robinson, S., Pogorski, S., Galea, S., \& Styra, R. (2004). SARS control and psychological effects of quarantine, Toronto, Canada. Emerging Infectious Diseases, 10(7), 1206-1212. https://doi.org/10.3201/eid1007.030703.

Hobfoll, S. E. (1989). Conservation of resources: A new attempt at conceptualizing stress. American Psychologist, 44(3), 513-524. https:// doi.org/10.1037/0003-066X.44.3.513.

Hobfoll, S. E. (2002). Social and psychological resources and adaptation. Review of General Psychology, 6(4), 307-324. https://doi.org/10. 1037/1089-2680.6.4.307.

Hopkins, V., \& Gardner, D. (2012a). The mediating role of work engagement and burnout in the relationship between job characteristics and psychological distress among lawyers. New Zealand Journal of Psychology, 41(1), 59-68.

Hopkins, V., \& Gardner, D. (2012b). The mediating role of work engagement and burnout in the relationship between job characteristics and psychological distress among lawyers. New Zealand Journal of Psychology, 41(1).

Institute for Public Policy Research. (2020). Covid-19: One in five healthcare workers could quit after pandemic unless urgent government action is taken, IPPR warns. https://www.ippr.org/news-andmedia/press-releases/covid-19-one-in-five-healthcare-workerscould-quit-after-pandemic-unless-urgent-government-action-istaken-ippr-warns

Johari, F. S., \& Omar, R. (2019). Exploring factors impacting on psychological well-being of health care workers. International Journal of Academic Research in Business and Social Sciences, 9(2). https:// doi.org/10.6007/ijarbss/v9-i2/5711.

Judge, T. A., \& Watanabe, S. (1993). Another look at the job satisfactionlife satisfaction relationship: A test of disaggregation hypothesis. Journal of Applied Psychology, 78(6), 939-948. https://doi.org/10. 1037/0021-9010.78.6.939.

June, Sethela \& Mahmood, R. (2011). The Relationship between Personjob Fit and Job Performance: A Study among the Employees of the Service Sector SMEs in Malaysia. International Journal of Business, Humanities and Technology, 1(2 (September 2011)). 2047-7031.

Kagan, M., \& Itzick, M. (2019). Work-related factors associated with psychological distress among social workers. European Journal of Social Work, 22(1), 30-42. https://doi.org/10.1080/13691457.2017. 1357021.

Kahn, R. L. (1980). The study of organizations (J. Katz, Daniel \& Kahn, Robert \& Adams (Ed.); 2nd ed., pp. 418-428).

Katz, D., \& Kahn, R. L. (1978). The social psychology of organizations (2nd ed.). Wiley.

Kessler, R., Barker, P., Colpe, L., Epstein, J., Gfroerer, J., \& Hiripi, E. (2003). Screening for serious mental illness in the general population. Kessler Psychological Distress Scale ( K10 ). Archives of General Psychiatry, 60(2), 184-189.

Kessler, R. C., \& McLeod, J. D. (1984). Sex differences in vulnerability to undesirable life events. American Sociological Review, 49(5), 620-631. https://doi.org/10.2307/2095420. 
Kossek, E. E., \& Thompson, R. J. (2016). Workplace flexibility: Integrating employer and employee perspectives to close the research-practice implementation gap. In E. L. \& a. T. (Eds.), The Oxford handbook of work and family (Vol. 255). Oxford University Press New York, NY.

Kock, N., \& Lynn, G. (2012). Lateral collinearity and misleading results in variance-based SEM: An illustration and recommendations. Journal of the Association for Information Systems, 13(7). https:// doi.org/10.17705/1 jais.00302.

Lee, S. A., Mathis, A. A., Jobe, M. C., \& Pappalardo, E. A. (2020). Clinically significant fear and anxiety of COVID-19: A psychometric examination of the Coronavirus Anxiety Scale. Psychiatry Research, 290(March), 113112. https://doi.org/10.1016/j.psychres. 2020.113112

Levinson, H., Kahn, R. L., Wolfe, D. M., Quinn, R. P., Snoek, J. D., \& Rosenthal, R. A. (1965). Organizational stress: Studies in role conflict and ambiguity. Administrative Science Quarterly, 10(1), 125. https://doi.org/10.2307/2391654.

Li, Y., Wang, Y., Jiang, J., Valdimarsdóttir, U. A., Fall, K., Fang, F., Song, H., Lu, D., \& Zhang, W. (2020). Psychological distress among health professional students during the COVID-19 outbreak. Psychological Medicine, 1-3. https://doi.org/10.1017/ S0033291720001555.

Mafune, K., Hiro, H., Inoue, A., Hino, A., Shigemura, J., Yamada, M., \& Okubo, T. (2019). Social support during emergency work and subsequent serious psychological distress: A cross-sectional study among emergency workers who responded to the Fukushima Daiichi nuclear power plant accident. Journal of Occupational and Environmental Medicine, 61(6), E240-E246. https://doi.org/10. 1097/JOM.0000000000001569.

Marini, I., Todd, J., \& Slate, J. R. (1995). Occupational stress among mental health employees. Journal of Rehabilitation Administration, 19(2), 123-130.

Mazza, C., Ricci, E., Biondi, S., Colasanti, M., Ferracuti, S., Napoli, C., \& Roma, P. (2020). A nationwide survey of psychological distress among italian people during the covid-19 pandemic: Immediate psychological responses and associated factors. International Journal of Environmental Research and Public Health, 17(9). https://doi.org/10.3390/ijerph17093165.

McKeever, V. (2020). Coronavirus lockdowns are making the working day longer for many. $C N B C$

McKibbin, W. J., \& Fernando, R. (2020). The global macroeconomic impacts of COVID-19: Seven scenarios. SSRN Electronic Journal. https://doi.org/10.2139/ssrn.3547729.

Murphy, K. R. (1989). Dimensions of job performance (p. 619). Testing: Theoretical and Applied Perspectives.

Shareena, P., \& Shahid, M. (2020). Work from home during COVID-19: Employees perception and experiences. Global Journal For Research Analysis, 9(5). https://doi.org/10.36106/gjra.

Padma, V., Anand, N. N., Gurukul, S. M. G. S., Javid, S. M. A. S. M., Prasad, A., \& Arun, S. (2015). Health problems and stress in Information Technology and Business Process Outsourcing employees. Journal of Pharmacy and Bioallied Sciences, 7. https:// doi.org/10.4103/0975-7406.155764.

Pavot, W., \& Diener, E. (2008). The satisfaction with life scale and the emerging construct of life satisfaction. Journal of Positive Psychology, 3(2), 137-152. https://doi.org/10.1080/ 17439760701756946.

Prasad, K., Vaidya, R., \& Kumar, V. (2018). Association among occupational stress factors and performance at workplace among agricultural research sector employees at Hyderabad, India. Pacific Business Review International (TSI), 10(7), 27-36.

Prasad, K., Vaidya, R., Kumar, V., \& Rekha, B. (2016). A comparative analysis on the causes of occupational stress among men and women employees and its effect on performance at the workplace of information technology sector, Hyderabad. International Journal of
Management Excellence, 7(2), 1-12. https://doi.org/10.17722/ijme. v7i2.261.

Prasad, K., \& Vaidya, R. W. (2020). Association among Covid-19 parameters, occupational stress and employee performance: An empirical study with reference to agricultural research sector in Hyderabad metro. Sustainable Humanosphere, 16(2), 235-253.

Ramarajan, L., \& Reid, E. (2013). Shattering the myth of separate worlds: Negotiating nonwork identities at work. Academy of Management Review, 38(4), 621-644. https://doi.org/10.5465/amr.2011.0314.

Roy, D., Tripathy, S., Kar, S. K., Sharma, N., Verma, S. K., \& Kaushal, V. (2020). Study of knowledge, attitude, anxiety \& perceived mental healthcare need in Indian population during COVID-19 pandemic. Asian Journal of Psychiatry, 51. https://doi.org/10.1016/j.ajp.2020. 102083.

Sarstedt, M., Ringle, C. M., \& Hair, J. F. (2017). Partial least squares structural equation modeling. In Handbook of Market Research (pp. 1-40). https://doi.org/10.1007/978-3-319-05542-8.

Sellick, S. M., \& Edwardson, A. D. (2007). Screening new cancer patients for psychological distress using the hospital anxiety and depression scale. Psycho-Oncology, 16(6), 534-542. https://doi.org/ 10.1002/pon.1085.

Shacham, M., Hamama-Raz, Y., Kolerman, R., Mijiritsky, O., Ben-Ezra, M., \& Mijiritsky, E. (2020). COVID-19 factors and psychological factors associated with elevated psychological distress among dentists and dental hygienists in Israel. International Journal of Environmental Research and Public Health, 17(8). https://doi.org/ 10.3390/ijerph17082900.

Steers, R. M., \& Rhodes, S. R. (1978). Major influences on employee attendance: A process model. Journal of Applied Psychology, 63(4), 391-407. https://doi.org/10.1037/0021-9010.63.4.391.

Stubbe, J. H., Posthuma, D., Boomsma, D. I., \& De Geus, E. J. C. (2005). Heritability of life satisfaction in adults: A twin-family study. Psychological Medicine, 35(11), 1581-1588. https://doi.org/10. 1017/S0033291705005374.

Stults-Kolehmainen, M. A., \& Sinha, R. (2014). The effects of stress on physical activity and exercise. In Sports Medicine (Vol. 44, issue 1). https://doi.org/10.1007/s40279-013-0090-5.

Sugiura, H., \& Iwata, I. (2016). Determinants of the stress of female managers in Japanese firms. Aichi University Journal of Economics, 202, 51-70.

Suryadevara, V., Adusumalli, C., Adusumilli, P. K., Chalasani, S. H., \& Radhakrishnan, R. (2020). Mental health status among the south Indian pharmacy students during Covid-19 pandemic quarantine period: A cross-sectional study. In medRxiv. https://doi.org/10. 1101/2020.05.08.20093708.

Taylor, M. R., Agho, K. E., Stevens, G. J., \& Raphael, B. (2008). Factors influencing psychological distress during a disease epidemic: Data from Australia's first outbreak of equine influenza. BMC Public Health, 8, 347. https://doi.org/10.1186/1471-2458-8-347.

van der Lippe, T., \& Lippényi, Z. (2020). Co-workers working from home and individual and team performance. New Technology, Work and Employment, 35(1), 60-79. https://doi.org/10.1111/ ntwe. 12153

Wang, C., Horby, P. W., Hayden, F. G., \& Gao, G. F. (2020a). A novel coronavirus outbreak of global health concern. The Lancet, 395(10223), 470-473. https://doi.org/10.1016/S0140-6736(20) 30185-9.

Wang, C., Pan, R., Wan, X., Tan, Y., Xu, L., Ho, C. S., \& Ho, R. C. (2020b). Immediate psychological responses and associated factors during the initial stage of the 2019 coronavirus disease (COVID-19) epidemic among the general population in China. International Journal of Environmental Research and Public Health, 17(5), 1729. https://doi.org/10.3390/ijerph17051729.

Wang, F., \& Boros, S. (2019). The relationship between physical activity, stress, life satisfaction and sleep quality. Journal of Physical 
Education and Sport, 19, 227-234. https://doi.org/10.7752/jpes. 2019.s1034.

Wersebe, H., Lieb, R., Meyer, A. H., Hofer, P., \& Gloster, A. T. (2018). The link between stress, well-being, and psychological flexibility during an acceptance and commitment therapy self-help intervention. International Journal of Clinical and Health Psychology, 18(1), 60-68. https://doi.org/10.1016/j.ijchp.2017.09.002.

Williams, K. J., \& Alliger, G. M. (1994). Role stressors, mood spillover, and perceptions of work-family conflict in employed parents. Academy of Management Journal, 37(4), 837-868. https://doi.org/ $10.2307 / 256602$.

World Health Organisation (WHO). (2020). WHO Director-General's Opening Remarks at the Media Briefing on COVID-19 - 11
March 2020. https://www.who.int/director-general/speeches/detail/ who-director-general-s-opening-remarks-at-the-media-briefing-oncovid-19\%2D\%2D-11-march-2020

Xia, A., Wang, B., Song, B., Zhang, W., \& Qian, J. (2019). How and when workplace ostracism influences task performance: Through the lens of conservation of resource theory. Human Resource Management Journal, 29(3), 353-370. https://doi.org/10.1111/ 1748-8583.12226.

Publisher's Note Springer Nature remains neutral with regard to jurisdictional claims in published maps and institutional affiliations. 